\title{
Development and fine structure of intracytoplasmic and epicytoplasmic meronts, merozoites and young macrogamonts of the cichlid fish swim bladder coccidium Goussia cichlidarum
}

\author{
Soo Hyun Kim, Ilan Paperna
}

Department of Animal Sciences, Faculty of Agriculture of the Hebrew University of Jerusalem, Rehovot 76-100, Israel

\begin{abstract}
The life history of the epicytoplasmic swim bladder coccidium Goussia cichlidarum was investigated in experimentally infected Oreochromis aurea $\times$ nilotica cichlid fish. Free merozoites were detected in various tissues from Day 7 post infection (p.i.). The swim bladder was reached via the blood stream and the rete mirabile. Merozoites were dividing by endodyogeny from Day 16 p.i. Epicytoplasmic meronts occurred in the swim bladder from Days 21 to 40 and gamogony took place from 32 to $47 \mathrm{~d}$ p.i. Detached, sporulated oocysts appeared from Day 50. By Day 70 all oocysts had completed sporulation. Prior to becoming epicytoplasmic, meronts and gamonts were intracytoplasmic, within the swim bladder epithelium. We describe the fine structure of free merozoites; merozoites in endodyogeny: intracytoplasmic young meronts and macrogamonts; and epicytoplasmic young, mature and dividing meronts, merozoites, and early-stage macrogamonts.
\end{abstract}

\section{INTRODUCTION}

Goussia cichlidarum (Eimeriidae: Eucoccidia; Apicomplexa) is an epicytoplasmic parasite of the swim bladder epithelium of cichlid fish (genera Oreochromis and Sarotherodon) in Africa and Israel (Landsberg \& Paperna 1985). The parasites are enclosed in a parasitophorous-like envelope which forms a hemidesmosal juncture with the underlying epithelial cells lining the swim bladder (Landsberg \& Paperna 1985, Paperna et al. 1986). Macrogamonts and their development to oocysts and sporocysts have been studied by both transmission electron microscopy (TEM; Paperna \& Landsberg 1985, Paperna et al. 1986) and scanning electron microscopy (SEM; Paperna \& Cross 1985). In the present communication we report on the course and timing of $G$. cichlidarum development and describe the ultrastructure of early intracytoplasmic stages from the swim bladder tissue, as well as that of epicytoplasmic meronts and young macrogamonts.

\section{MATERIALS AND METHODS}

Fish hosting both natural and experimental infections were juveniles $(<50 \mathrm{~mm}$ total length) of the Israelicultured hybrid tilapia Oreochromis aurea $\times$ nilotica. They were either taken from experimental hatchery stocks, or reared from the yolksac stage under controlled conditions. Fish were experimentally infected by feeding on sporocyst-infected swim bladders which had been dissected from naturally infected fish. Freedom from prior infection was verified by examining 10 fish of the same stock prior to feeding, and 10 from a control, non-infected group at the end of the experimental period. Two series of infections were carried out, the first with 31 fish 20 to $40 \mathrm{~mm}$ long ( 4 to $8 \mathrm{wk}$ old), and the second with 70 fish 12 to $18 \mathrm{~mm}$ long ( 2 to $4 \mathrm{wk}$ old). Fish were kept in aerated containers of various sizes, in a heat-regulated room at $24^{\circ} \mathrm{C}$. Schedules for examination of the fish varied with the different experiments. Presence of infection in the fish organs - intestine, liver, spleen, kidneys and swim bladder - until Day 15 post 

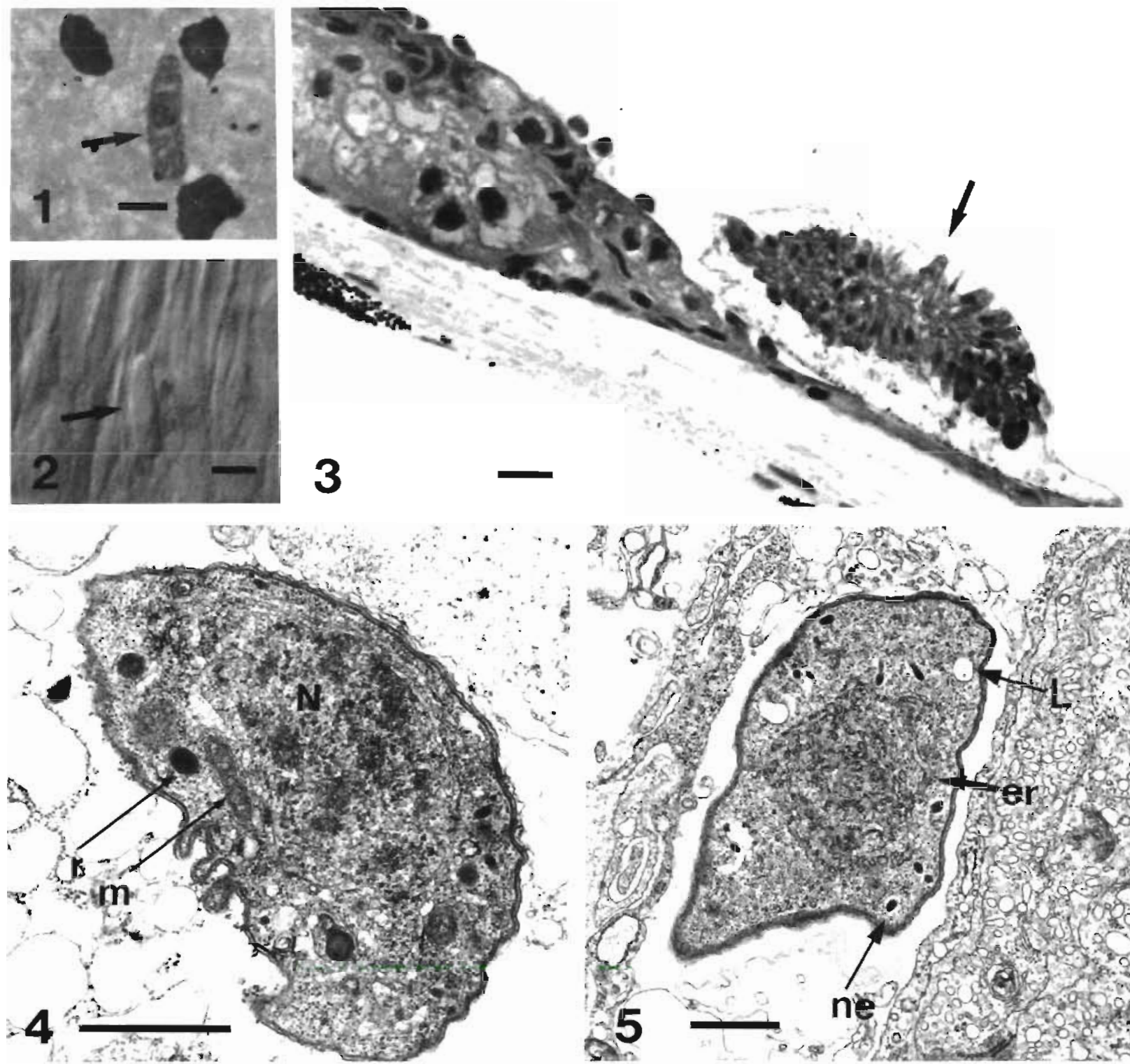

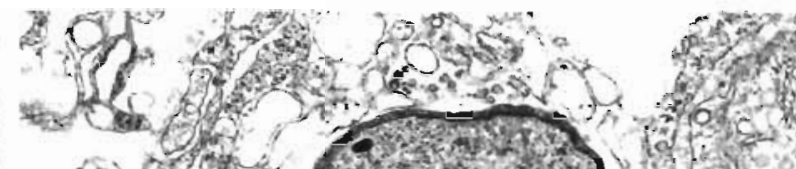
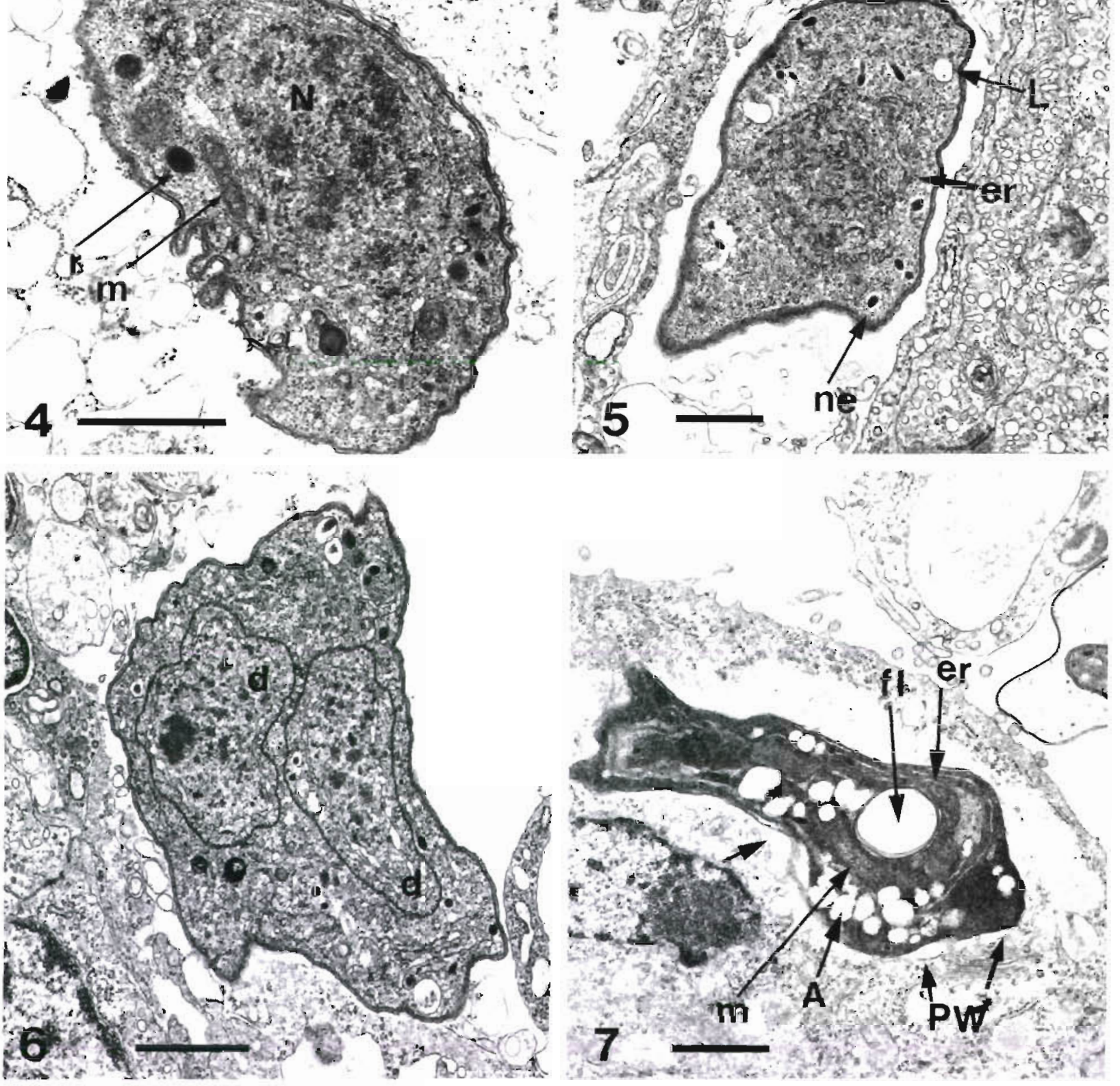
infection (p.i.), and thereafter only in swim bladders was determined by Nomarski microscopic examination of fresh, pressed tissue, by smears and by histology Infected swim bladders were further studied by TEM.

Tissues smears were air-dried, fixed in absolute methanol and stained for $1 \mathrm{~h}$ with a pH 6.8-buffered $10 \%$ Giemsa solution. For histology, swim bladders were cut open and fixed in $10 \%$ neutral buffered formalin, and then embedded in a glycol methacrylate resin (from Polyscience, or LKB's 'Historesin'). Sections (3 to $4 \mu \mathrm{m}$ thick) were cut with a glass knife on a Sorval JB4 microtome and stained with Meyer's hamatoxylin-eosin. For TEM, pieces from the swim bladders were fixed in Karnowski for $4 \mathrm{~h}$ at room temperature $\left(22\right.$ to $26^{\circ} \mathrm{C}$ ) or for 24 h at $4{ }^{\circ} \mathrm{C}$, rinsed repeatedly in $0.1 \mathrm{M}$ cacodylate buffer, pH 7.4, and post-fixed in $1 \%$ osmium tetroxide, in the same buffer, for $1 \mathrm{~h}$. Following rinses in buffer, the material was serially dehydrated in ethanol and embedded in Epon. Thin sections cut by a Reichert Ultracut ultratome with diamond knife were stained on a grid with uranyl acetate and lead citrate and examined with a Jeol 100CX TEM. Semithin sections for light microscopic studies were cut in an ultratome with a glass knife and stained in Toluidine Blue.

\section{RESULTS}

\section{Course of development (Table 1)}

All fish examined later than $20 \mathrm{~d}$ after infecting were found to be infected. Earlier infections were only detected in some of the fish.

\section{Early stages in the tissues}

Sporozoites (with crystalloid bodies) were found in smears prepared from the intestine of one fish $5 \mathrm{~d}$ p.i. Free merozoites were detected in smears from the spleen, kidney and liver (11-12 × 3-4 $\mu \mathrm{m}$ in size), from Day 7 p.i. (Fig. 1), and in smears and fresh impressions $(11-12 \times 3-4 \mu \mathrm{m}$ in size) from the rete mirabile on Days 10 to 16 p.i. (Fig. 2). Merozoites dividing by endodyogeny were found $16 \mathrm{~d}$ p.i. in the intercellular spaces of the rete mirabile and in subepithelial swim bladder tissue. Young intracytoplasmic meronts and gamonts were found in the swim bladder epithelium and in the underlying connective tissue until Day 37 p.i.

Table 1. Goussia cichlidarum infecting Oreochromis aurea $\times$ nilotica. Summary of the developmental stages found in fish sacrificed at different times post-infection. InSp: sporozoites in intestine; P-SwSt: pre-swim bladder stages; YMer: young meronts FM: free merozoites; $M<20$ : meronts yielding less than 20 merozoites; $M \geq 50$ : meronts yielding $50+$ merozoites; YMa: young macrogamonts; Mi: microgamonts; MM: mature macrogamonts; OO: oocysts-sporoblasts; SpO: sporulated oocysts. ( $\left.{ }^{\prime}\right)$ and (') indicate the 2 different infected groups. The number of + symbols indicates the relative level of infection, from low to high

\begin{tabular}{|c|c|c|c|c|c|c|c|c|c|c|c|}
\hline Days p.i. & $\ln \mathrm{Sp}$ & P-SwSt & YMer & FM & $M<20$ & $M \geq 50$ & YMa & $\mathrm{Mi}$ & $\mathrm{MM}$ & 00 & $\mathrm{SpO}$ \\
\hline \multicolumn{12}{|l|}{1} \\
\hline 5 & ++ & & & & & & & & & & \\
\hline 7 & & ++ & & & & & & & & & \\
\hline $10-15$ & & $++t$ & & & & & & & & & \\
\hline $20-21$ & & & & + & & $t+t+$ & & & & & \\
\hline $26^{\circ}$ & & & ++ & & ++ & ++++ & + & & & & \\
\hline $30^{\circ}$ & & & + & & & & + & & & & \\
\hline 32 & & & & & & $++t$ & ++ & ++ & ++ & & \\
\hline $34^{\circ}$ & & & & & & & + & ++ & & & \\
\hline 37 & & & +++ & +++ & & ++++ & +++ & + & $+++t$ & ++++ & \\
\hline $39^{\circ}$ & & & & +++ & & +++ & & + & + & & \\
\hline $39 \cdots$ & & & & & & & & + & ++ & ++++ & \\
\hline $42^{\circ}$ & & & & & & & & & ++++ & ++++ & \\
\hline $47^{\circ}$ & & & & & & & & & + & ++++ & \\
\hline $58^{\circ}$ & & & & & & & & & & ++++ & ++++ \\
\hline $74^{\circ}$ & & & & & & & & & & & ++++ \\
\hline
\end{tabular}

Figs. 1 to 7. Goussia cichlidarum infecting Oreochromis aurea $\times$ nilotica. Fig. 1. Free merozoite in Giemsa-stained smear from the kidney. Scale bar $=5 \mu \mathrm{m}$. Fig. 2. Free merozoite in fresh impression from the rete mirabile. By Nomarski; scale bar $=5 \mu \mathrm{m}$. Fig. 3 . Mature, dividing meront attached to the epithelium lining the swim bladder. Methacrylate histology; scale bar $=10 \mu \mathrm{m}$. Figs. $4 \&$ 5. Free merozoite in the swim bladder tissue. Scale bar $=1 \mu \mathrm{m}$. Fig. 6 . Merozoite in endodyogeny in the swim bladder tissue. Scale $\overline{b a r}=1 \mu \mathrm{m}$. Fig. 7. Young meront within a parasitophorous vacuole, in an epithelial cell lining the swim bladder. Scale bar $=1 \mu \mathrm{m}$. A: amylopectin granules; d: daughter cells; er: endoplasmic reticulum; fl: folds or invaginations; L: lipid vacuole; m: mitochondrion; N: nucleus; ne: micronemes; PW (\& arrows): parasitophorous vacuole wall; r: rhoptries. TEM 

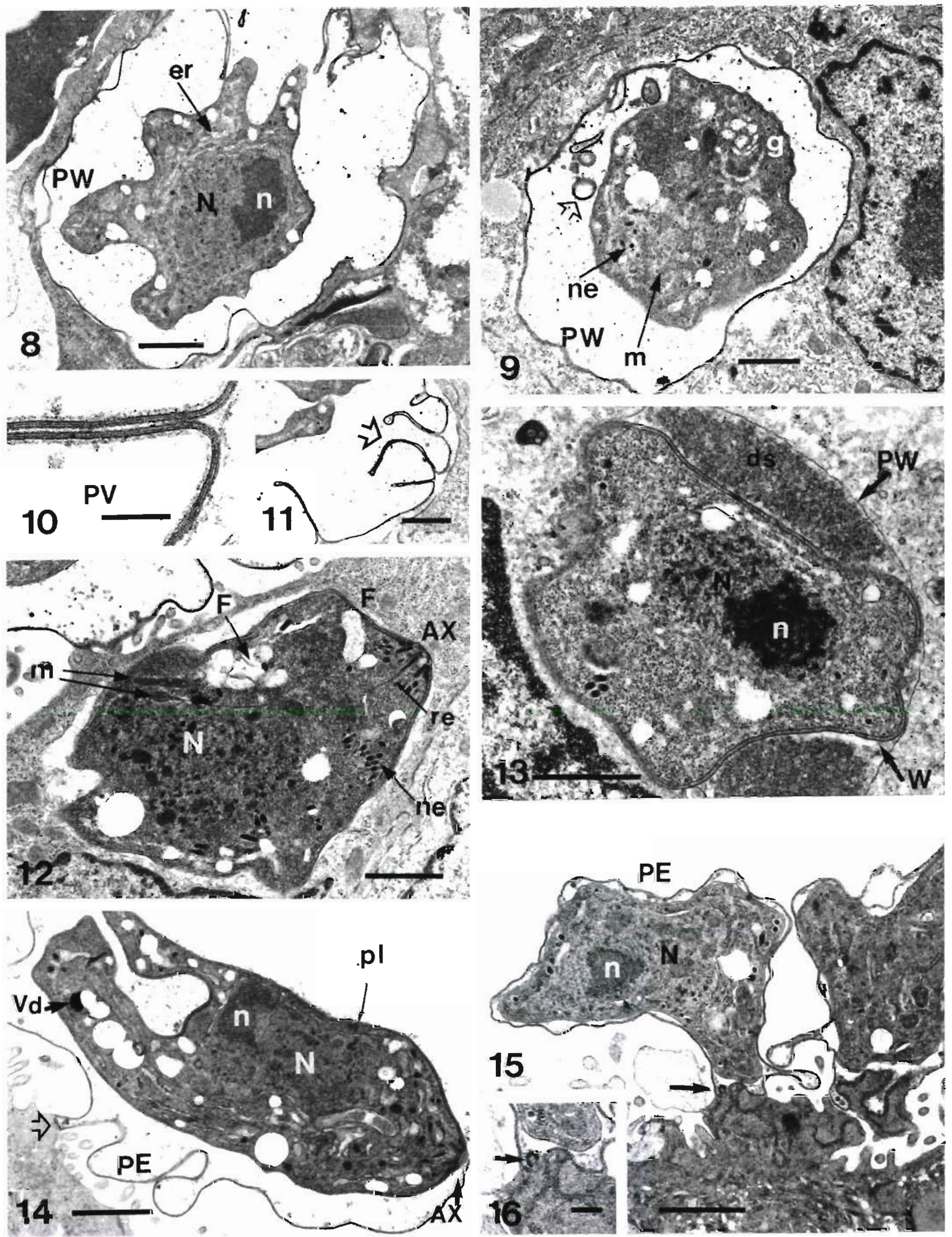


\section{Epicytoplasmic development in the swim bladder}

Epicytoplasmic, dividing meronts $(28-56 \times 14-28 \mu \mathrm{m}$ in size) were detected in the swim bladder from Day 21 p.i. Mature meronts yielded 16 to 120 merozoites (Fig. 3). Segmenting meronts sometimes became detached from the epithelial lining. Young and dividing epicytoplasmic meronts and release of merozoites into the swim bladder lumen occurred up to $40 \mathrm{~d}$ p.i. After becoming detached from the parent meront, merozoites were seen to undergo endodyogeny. Young epicytoplasmic gamonts appeared from Day 32 p.i. Gamogony took place until $47 \mathrm{~d}$ p.i., at which time oogony and sporogony commenced. Oocysts containing mature sporocysts occurred in the swim bladder lumen from Day 50 p.i. The entire parasite population completed its developmental process by reaching the ripe sporocyst stage, each sporocyst containing 2 active sporozoites, by Days 65 to 70 (Table 1). The length of time that sporocysts remain viable in the swim bladder has not yet been determined.

\section{Electron microscopy}

Early tissue stages

Free merozoites (Figs. 4 \& 5), some dividing by endodyogeny (Fig. 6), in the swim bladder tissues were bound by a 3-membrane pellicle. Sections (4-6 6 -2-3 $\mu \mathrm{m}$ ) revealed many micronemes, rhoptries (some with their electron-dense contents partially or completely extracted), smooth as well as rough endoplasmic reticulum, a variable number of mitochondria, and in some merozoites a lipid vacuole.

Young intracytoplasmic meronts were found inside swim bladder epithelial cells, within parasitophorous vacuoles. The latter were bound by a single fine membrane (Fig. 7), and sometimes by an additional thick trilaminate envelope (Figs. 8 to 10), forming deep, inward folds (Figs. $9 \& 11$ ). The meronts $(4-5 \times 2-4 \mu \mathrm{m}$ in size) varied in shape, were sometimes invaginated, were bound by a 3-layered, pellicular-type wall, and contained a nucleus with a large, eccentric nucleolus
(Fig. 8) and cytoplasm with an extensive, circular network of endoplasmic reticulum, several large mitochondria (Fig. 7), a Golgi apparatus (Fig 9), a variable number of micronemes and numerous amylopectin granules (Figs. $7 \& 9$ ).

Young intracytoplasmic macrogamonts $(3-6 \times 2-5$ $\mu \mathrm{m}$ in size) were located within a parasitophorous vacuole with a single membrane wall (Figs. 12 \& 13). Some of the parasitophorous vacuoles also contained a dense, granular substance (Fig. 13). The macrogamonts were bound by a 2-membrane wall, and retained an apical complex, rhoptries and micronemes, a nucleus with a large, aggregated-matrix nucleolus (Fig. 13), a variable number of food vacuoles (some containing the same flocculent substance filling the parasitophorous vacuole), prolonged mitochondria filled with a moderately to highly electron-dense granular substance, a lipid vacuole and a few amylopectin granules.

Epicytoplasmic stages in the swim bladder

\section{Meronts}

Very young epicytoplasmic asexual stages still retained merozoite features - elongate $(5-6 \times 2-3 \mu \mathrm{m})$, with a prominent apical complex and an anterolateral micropyle (Fig. 14). Young meronts gradually became rounded (3-4 × 2-3 $\mu \mathrm{m}$; Fig. 15) but still retained their apical complex. Parasitophorous envelopes enclosing the young meronts formed a prominent hemidesmosal juncture with the host epithelial cell and a very distinct tube which seemed to be extending from the juncture complex (Fig. 16). Other young meronts $(5-10 \times 3-5$ $\mu \mathrm{m})$, rounded but with inward folds (Figs. $17 \& 18$ ), were similar to the intracytoplasmic young meronts: they had dense, perinuclear, often concentric endoplasmic reticulum and a prominent Golgi apparatus. All of these meronts were bound by a 3-layered pellicle, had a nucleus containing a large, usually eccentric nucleolus and exhibited various amounts of lipid vacuoles and amylopectin granules, micronemes and rhoptry residues (vacuoles containing remains of an electron-dense substance) (Figs. 14, $15 \& 17$ ).

Figs. 8 to 16. Goussia cichlidarum infecting Oreochromis aurea $\times$ nilitica. Figs. $8 \& 9$. Young intracytoplasmic meronts in the swim bladder epithelial cells, enclosed within parasitophorous vacuoles with thick trilaminate (PW) and folded (open arrow) walls. Figs. $10 \& 11$. Details of the parasitophorous vacuole (PV) wall and folds (open arrow). Figs. 12 \& 13. Intracytoplasmic macrogamonts in the swim bladder epithelium. Fig. 14. Young, elongate epicytoplasmic meront. Fig. 15. Young rounded epicytoplasmic meronts. Arrow: parasitophorous vacuole juncture to the host cell. Fig. 16. Hemidesmosal juncture of a young meront's (cf. Fig. 15) parasitophorous vacuole, with a tube (arrow) to the underlying host cell. Open arrow: parasitophorus vacuole juncture to the host cell. AX: apical complex; ds: dense granular substance; F: food vacuole; g: Golgi apparatus; n: nucleolus; ne: micronemes; PE: parasitophorous envelope; $\mathrm{pl}$ : micropyle; PV: parasitophorous vacuole; re: rhoptry extension into the apical complex; Vd: rhoptry residae; W: trilaminated wall; other abbreviations as in Figs. 1 to 7 . Scale bars $=1 \mu \mathrm{m}$ in Figs. 8,9 and 11 to $15 ; 0.2 \mu \mathrm{m}$ in Figs. 10 and 16 

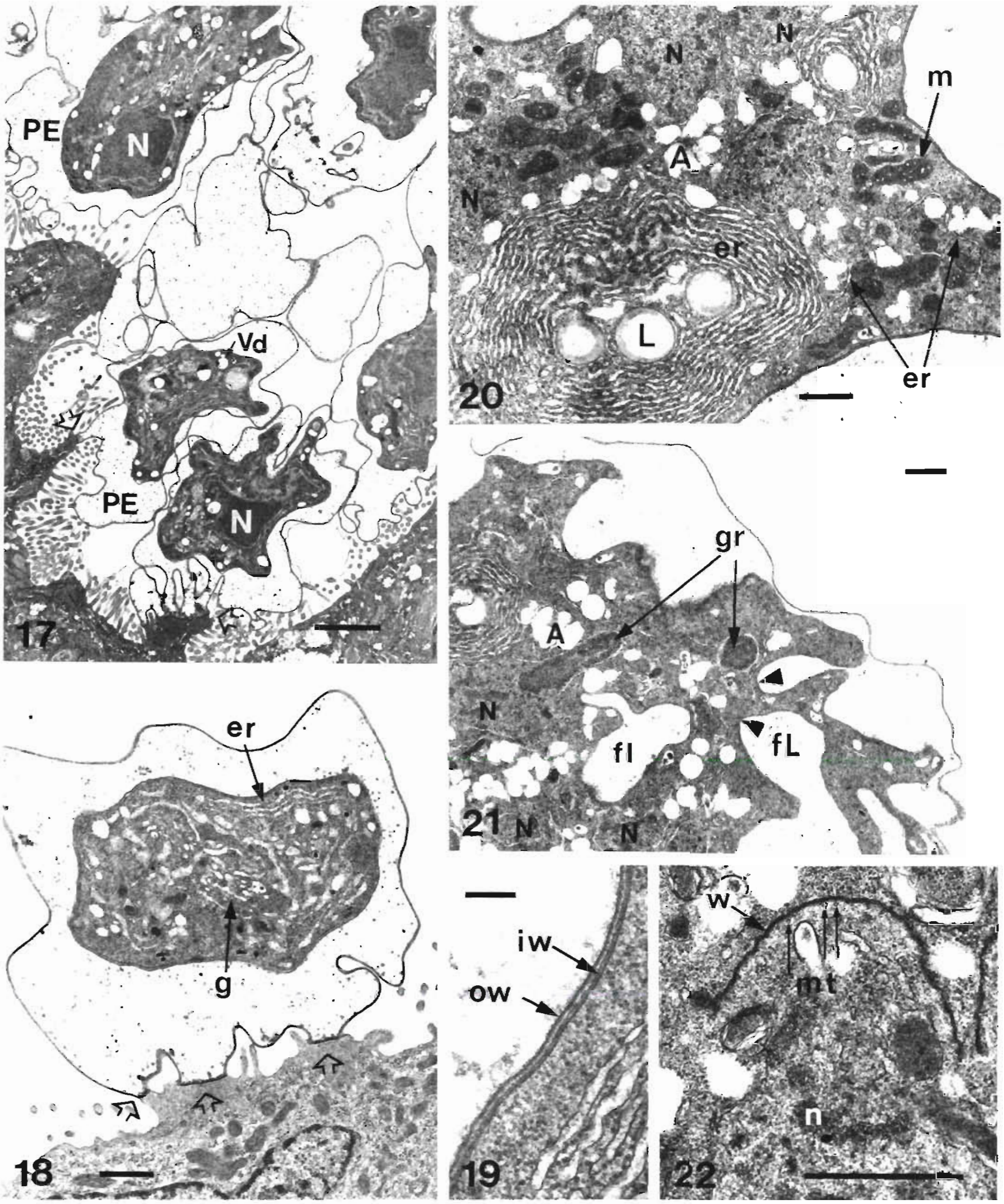
Large differentiating and mature meronts (Figs. 3 \& 20 to 23 ) retained the merozoite-type pellicular wall, i.e. an outer membrane and 2 adjoining inner membranes (Fig. 19). Mature and dividing meronts (Figs. 20 \& 21) had extremely folded surfaces. Their cytoplasm contained numerous conspicuous lipid vacuoles surrounded by large concentric bundles of endoplasmic reticulum (Fig. 20) and diverse organelles, of which the most numerous were tubular-type mitochondria with dense matrices, amylopectin granules and endoplasmic reticulum cisternae (Fig. 20). Additional organelles included membrane-bound aggregates of large granules or ribosomes (Fig, 21). Meronts divided into merozoites by endomerogony (endopolygeny) (Figs. 22 \& 23). Primordial merozoites emerging from the perimeter of the meront nuclei were demarkated by a 2 -membrane boundary and contained sub-pellicular microtubules (Fig. 22), conoid complexes at the apices, a rounded, electron-dense organelle (the presumed rhoptry anlagen), and a mitochondrion (Fig. 23). Golgi apparatuses accompanied each emerging merozoite. At this stage, meront cytoplasm also contained numerous round and branched endoplasmic reticulum cisternae, mitochondria, the above-mentioned membraneenclosed inclusion of granular substance, many amylopectin granules of various sizes and a few vesicles containing flocculent material (Fig. 23).

\section{Merozoites}

Merozoites formed from rosettes towards the end of merogonous division $(10 \times 2.5 \mu \mathrm{m}$ in size $)$ and contained a nucleus with a distinct, eccentric nucleolus (Fig. 24), often surrounded by concentric endoplasmic reticulum. Endoplasmic reticulum and cisternae were abundant throughout the cytoplasm, which also contained a varying numbers of rhoptries, a few micronemes, some mitochondria (Fig. 25) and many amylopectin granules (Fig. 24). Also present were free merozoites, with nuclei containing scattered chromatin and perinuclear mitochondria, a sparse network of endoplasmic reticulum, few rhoptries, very few micronemes and no amylopectin granules. In one merozoite cross section it was possible to count 25 sub-pellicular microtubules (Fig. 26). A third type of merozoite $(6-7 \times$ 1-2 $\mu \mathrm{m}$ in size), in the same swim bladder, had 4 to 6 pellicular folds on either side of its mid-zone (Fig. 27). Each fold, measuring $0.4 \mu \mathrm{m}$, contained cytoplasm in addition to the 3-layered pellicle (Fig. 28). The merozoites were still contained within a parasitophorous envelope. They had nuclei containing patchy chromatin and their apical end contained more rhoptries and micronemes than that of the other merozoites. The cytoplasm contained a moderate number of amylopectin granules.

\section{Young epicytoplasmic macrogamonts}

Young macrogamonts $(9-15 \times 7-9 \mu \mathrm{m}$ in size) were characterized by a nucleus containing a large nucleolus made up of an aggregated, electron-dense substance (Fig. 29). They were bound by the same type of pellicle, i.e. a triple-membrane wall, bordering merozoites and meronts (Fig. 30), and they retained their apical complex (Fig. 29 \& 30). Their cytoplasm abounded with organelles: a Golgi apparatus adjoining the nucleus, elongate or rounded mitochondria, scattered endoplasmic reticulum with many cisternae, and amylopectin granules (Figs. 29 \& 30). Food vacuoles of various sizes contained either the same flocculent substance seen in the parasitophorous vacuole or granular, electron-dense particles and multilaminate bodies (Fig. 31).

\section{DISCUSSION}

Sporulated oocysts from the swim bladder apparently are already infective. Overstreet et al. (1984) predicted that members of the genus Goussia would be mostly heteroxenous. However, to date, obligatory heteroxenity has only been demonstrated in Calyptospora funduli (Fournie \& Overstreet 1983). Although sporozoites of $G$. carpelli and $G$. subepithelialis have been shown to survive in potential intermediate hosts, such as tubificid worms (Steinhagen 1991a) and grass shrimps for $G$. carpelli (Kent \& Hedrick 1985), and to be transmitted when the latter are fed to fish, direct transmission of these species has also been reported (Marincek 1973, Steinhagen \& Körting 1988, Lukes et al. 1991). Kent \& Hedrick (1985) failed to obtain direct infection of $G$. carpelli because they used oocysts extracted from the gut rather than the feces. Other

Figs. 17 to 22. Goussia cichlidarum infecting Oreochromis aurea $\times$ nilotica. Figs. $17 \& 18$. Young epicytoplasmic folded meronts in the swim bladder lumen, showing extensive concentric, perinuclear endoplasmic reticulum (er); open arrows mark junctures of the parasitophorous envelope with the host epithelium. Fig. 19. Wall of mature meront iw: inner 2-membrane wall; ow: outer wall. Figs. 20 \& 21. Details of a mature meront, before the appearance of merozoite primordia bold arrow: folded surface. Fig. 22. Details of an emerging merozoite. fl: folded surface; gr: membrane-bound granular inclusions; mt: microtubules; w: 2-membrane wall; other abbreviations as in Figs. 1 to 16. Scale bars $=0.2 \mu \mathrm{m}$ in Fig. 19 and $1 \mu \mathrm{m}$ in Figs. 17,18 and 20 to 22 


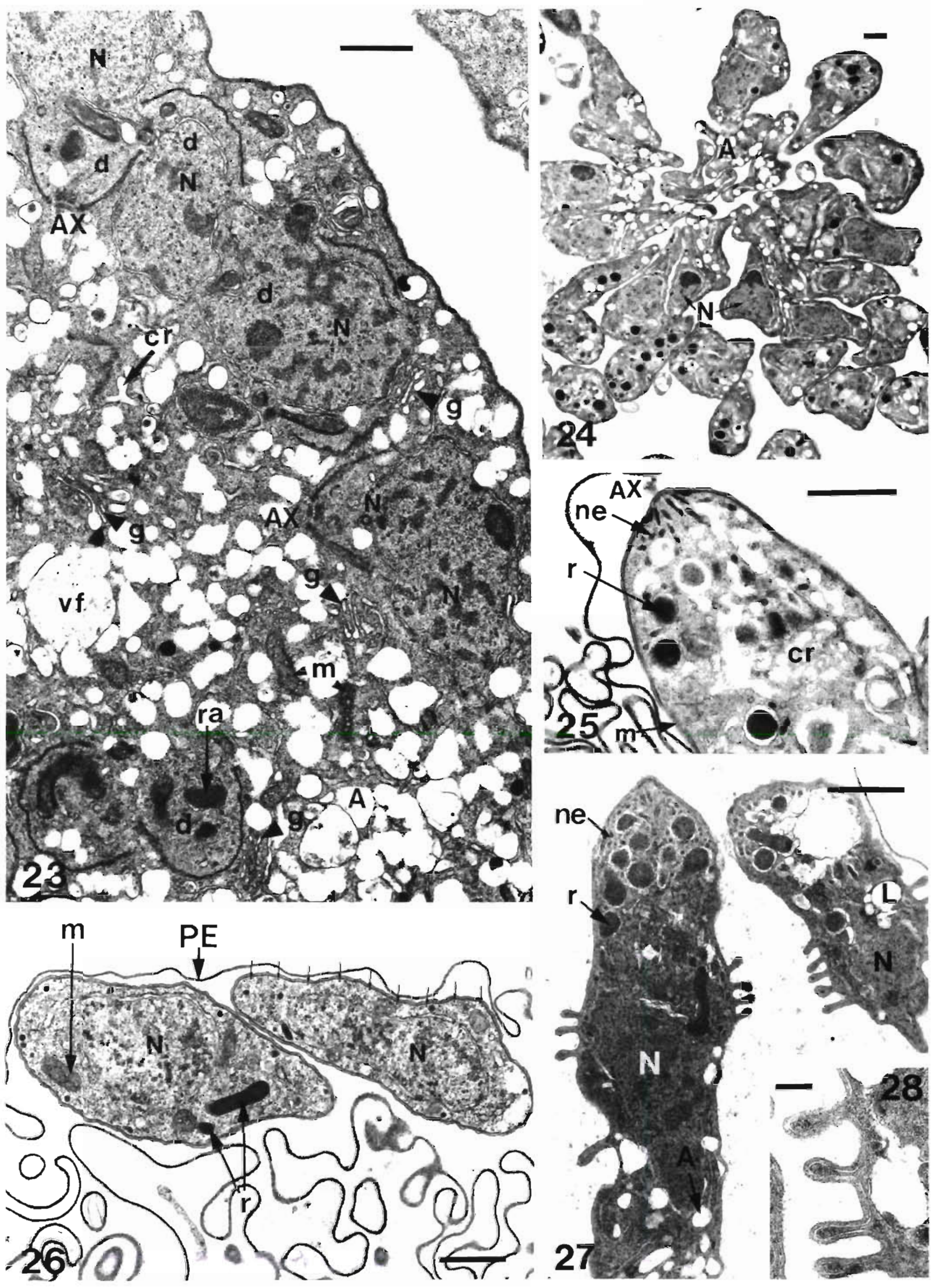



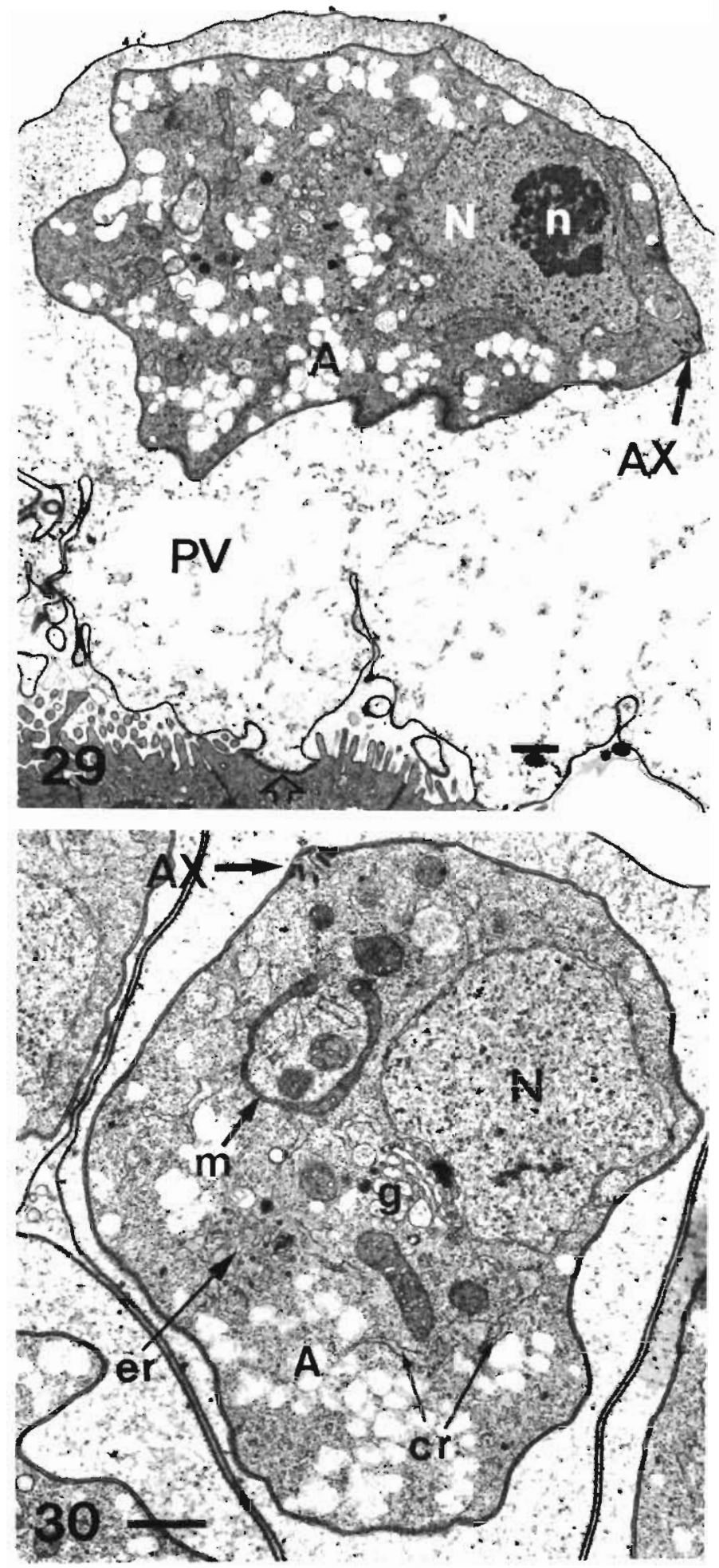

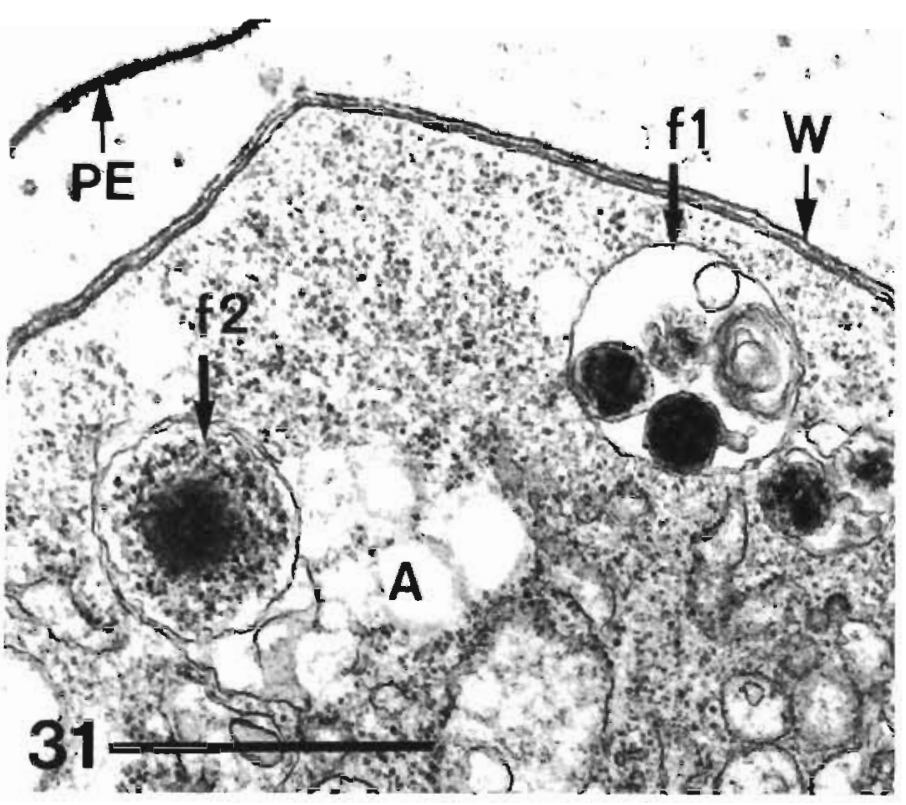

Figs. 29 to 31 Goussia cichlidarum infeeting Oreochromis aurea $\times$ nulotica. General and close-up views of young, epicytoplasmic macrogamonts. f1 food vacuole containing particles; f2: food vacuole containing concentrically aggregated granular substance, parasitophorous envelope junction with host cell is marked by open arrow in Fig. 29 Other abbrevia-

tions as in Figs. 1 to 16 and 23 to 28. Scale bars $=1 \mu \mathrm{m}$

species with which direct transmission has been reported are G. iroquoina (Paterson \& Desser 1981a) and Eimeria s.l. vanasi (Kim \& Paperna unpubl.). However, since sporocysts can only be released from infected swim bladders if their host fish dies or is predated upon (and provided they are capable of surviving the transit via a non-host piscine gut), infection in nature is usually transmitted via necrophagous or coprophagous paratenic hosts.

The development of Goussia cichlidarum from initial contamination to infective sporocyst stages takes about $50 \mathrm{~d}$ (at temperatures of 24 to $28^{\circ} \mathrm{C}$ ). This is quite long, as compared to the intestinal piscine coccidaa G. carpelli ( 6 to $10 \mathrm{~d}$ at $20^{\circ} \mathrm{C}$; Lom et al. 1991), G. iroquoina (11 to $12 \mathrm{~d}$ at $20^{\circ} \mathrm{C}_{\text {; }}$ Paterson \& Desser 1984) and Eimeria s.l. vanasi $\left(7\right.$ to $9 \mathrm{~d}$ at $25^{\circ} \mathrm{C}$; Kim \& Paperna unpubl.), but comparable to the extra-intestinal, piscine liver coccidium Calyptospora funduli. In the latter, young meronts are first seen $5 \mathrm{~d}$ p.i., first generation merozoites by Day 10, differentiating gamonts by Days

Figs 23 to 28. Goussia cichlidarum infectıng Oreochromis aurea $\times$ nulotica. Fig 23. Meront dividing endogenously with emerging merozoite primordia. Fig. 24. Merozoite formation at the end of meront division. Fig. 25. Detalls of a newly formed merozoite Fig 26. Merozoites of a different generation than those shown in Figs. 24 \& 25, still located within a parasitophorous envelope. Thin arrows indicate sub-pellicular microtubules. Fig. 27. Merozoites with lateral pellicular folds. Fig. 28. Enlarged view of the pellicular folds. cr: cisternae; ra: rhoptry anlagen; vf: vesicles with flocculent matenal; other abbreviations as in Figs 1 to 16 Scale bars $=1 \mu \mathrm{m}$ in Figs. 23 to 27 and $0.2 \mu \mathrm{m}$ in Fig. 28 
15 to 20 , fertilization by Days 19 to 26, sporoblasts by Days 26 to 30 and sporozoites by Day 60 (at $24^{\circ} \mathrm{C}$; Solangi \& Overstreet 1980)

The present study demonstrates that (1) the parasite reaches the swim bladder via the bloodstream and the rete mirabile; (2) en route, sporozoites lose their refractory body and undergo division by endodyogeny; and (3) meronts and gamonts (or only macrogamonts) go through an intracytoplasmic stage before becoming epicytoplasmic.

Invasion via the bloodstream seems to be the route by which parasites reach extra-intestinal sites. Nonetheless, we lack substantiative data from the other extra-intestinal coccidia investigated to date (Solangi \& Overstreet 1980, Morrison \& Poynton 1989). Endodyogeny in Eimeria vanasi merozoites has been previously observed before the onset of differentiation into meronts and following merogonous divisions (Paperna 1991, Kim \& Paperna 1992).

The occurrence of both intracytoplasmic meronts and macrogamonts in the swim bladder epithelium suggests that all epicytoplasmic generations, rather than just the initial one, begin their development within the cells of the swim bladder epithelium. The process by which the intracytoplasmic forms relocate themselves to an epicytoplasmic position remains, however, unknown. Transition from intracytoplasmic to epicytoplasmic locations has been observed in Eimeria vanasi - without, however, determination of the direction of migration being possible (Paperna 1990, Kim \& Paperna 1992).

Meronts gave rise to merozoites by endomerogony (endopolygeny). This form of division has been also observed in Goussia carpelli (Steinhagen 1991b) and during the second merogonous division of Eimeria iroquoina (Paterson \& Desser 1981b).

The finding of 3 forms of merozoites suggests the occurrence of at least 2 merogony generations in the life cycle of Goussia cichlidarum, similar to what has been shown in the course of development of Eimeria iroquoina (Pattern \& Desser 1981a).

The persistence of a merozoite-type pellicle in both meronts and macrogamonts (also microgamonts; Paperna unpubl.) to mature stages is unusual among vertebrate coccidia, but may be characteristic of some piscine coccidia. A pellicle-type cell wall is also retained in meronts and macrogamonts, but not in the microgamonts, of Goussia zarnowskii (Jastrzebski \& Komorowski 1990). Another peculiar feature is the pellicular folds occurring in one of the 3 generations of merozoites observed in the swim bladder. These pellicular folds closely resemble those seen in intraerythrocytic gamonts of frog and skink haemogregarines (Desser \& Weller 1973, Paperna \& Boulard unpubl.).

\section{LITERATURE CITED}

Desser, S. S., Weller, I. (1973). Structure, cytochemistry, and locomotion of Haemogregarina sp. from Rana berlandieri, J. Protozool. 20: 65-73

Fournie, J. W., Overstreet, R. M. (1983). True intermediate hosts for Eimeria funduli (Apicomplexa) from estuarine fishes. J. Protozool 30: 672-675

Jastrzebski, M., Komorowski, Z. (1990). Light and electron microscopic studies on Goussia zarnowskii (Jastrzebski 1982): an intestinal coccidium parasitizing the three spined stickleback, Gasterosteus aculeatus (L.). J. Fish Dis. 13: $1-12$

Kent, M. L., Hedrick, R. P. (1985). The biology and associated pathology of Goussia carpelli (Leger and Stankovitch) in Goldfish Carassius auratus (Linnaeus). Fish Pathol. 20: 485-494

Kim, S. H., Paperna, I. (1992). Fine structure of epicytoplasmic siages uf Eimferid Vandsi from the gui of cichiid fish. Dis. aquat. Org. 12: 191-197

Landsberg, J. H., Paperna, I. (1985). Goussia cichlidarum n. sp. (Barrouxiidae, Apicomplexa), a coccidian parasite in the swimbladder of cichlid fish. Z. Parasitenkd. 71. 199-212

Lom, J., Steinhagen, D., Körting, W., Dykova, I. (1991). Oocyst formation in the coccidian parasite Goussia carpelli. Dis. aquat. Org. 10: 203-209

Lukes, J., Steinhagen, D., Körting, W. (1991). Goussia carpelli (Apicomplexa, Eimeriorina) from cyprinid fish: field observations and infection experiments. Angew. Parasitol. 32 $149-153$

Marincek, M. (1973). Development d'Eimeria subepithelialis (Sporozoa, Coccidia) - parasite de la carpe. Acta Protozool 12: $166-174$

Morrison, C. M., Poynton, S. L. (1989). A new species of Goussia (Apicomplexa, Coccidia) in the kidney tubules of the cod Gadus morhua L. J. Fish Dis. 12: 533-560

Overstreet, R. M., Hawkins, W. E. Fournie, J. W (1984). The coccidian genus Calyptosporan. sp. and the family Calyptosporidae n. fam. (Apicomplexa), with members infecting primarily fishes. J. Protozool. 31. 332-339

Paperna, I. (1990). Fine structure of the gamonts of Eimeria (s.l.) vanasi, a coccidium from the intestine of cichlid fishes Dis. aquat. Org. 9: 163-170

Paperna, I. (1991). Fine structure of Eimeria (s.l.) vanasi merogony stages in the intestinal mucosa of cichlid fishes Dis. aquat. Org. 10: 195-201

Paperna, I., Cross, R. H. M. (1985). Scanning electron microscopy of gamogony and sporogony stages of Goussia cichlidarum a coccidian parasite in the swimbladder of cichlid fishes. Protistologica 21: 473-479

Paperna, I., Landsberg, J. H. (1985). Ultrastructure of oogony and sporogony in Goussia cichlidarum Landsberg and Paperna 1985, a coccidian parasite in the swimbladder of cichlid fish. Protistologica 21: 349-359

Paperna, I., Landsberg, J. H., Feinstein, N. (1986). Ultrastructure of the macrogamont of Goussia cichlidarum Landsberg and Paperna, 1985, a coccidian parasite in the swim bladder of cichlid fish. Ann. Parasitol. hum. comp. 61 $511-520$

Paterson, W. B., Desser, S. S. (1981a). Ultrastructure of macrogametogenesis, macrogametes and young oocysts of Elmeria iroquoina Molnar and Fernando, 1974 in experimentally infected fathead minnows (Pimephales promelas, Cyprinidae). J. Parasitol. 67: 496-504

Paterson, W. B., Desser, S. S. (1981b). An ultrastructural study of Eimeria iroquoina Molnar \& Fernando, 1974 in experi- 
mentally infected fathead minnows (Pimephales promelas, Cyprinidae) 3. Merogony. J. Protozool. 28: 302-308

Paterson, W. B., Desser, S. S. (1984). Ultrastructural observations on fertilization and sporulation in Goussia iroquoina (Molnar and Fernando, 1974) in experimentally infected fathead minnows (Pimephales promelas, Cyprinidae). J. Parasitol. 70: 703-711

Solangi, M. A., Overstreet, R. M. (1980). Biology and pathogenesis of the coccidium Eimeria funduli infecting killifishes. J. Parasitol. 66: 513-526

Steinhagen, D. (1991a). Ultrastructural observations on

Responsible Subject Editor: W. Körting, Hannover, Germany sporozoite stages of piscine Coccidia: Goussia carpelli and $G$. subepithelialis from the intestine of tubificid oligochaetes. Dis. aquat. Org. 10: 121-125

Steinhagen, D. (1991b). Ultrastructural observations on merogonic and gamogonic stages of Goussia carpelli (Apicomplexa, Coccidia) in experimentally infected common carp Cyprinus carpio. Eur. J. Protistol. 27: 71-78

Steinhagen, D., Körting, W. (1988). Experimental transmission of Goussia carpelli (Leger \& Stankovitch, 1921; Protista: Apicomplexa) to common carp. Cyprinus carpio L. Bull. Eur. Ass. Fish Pathol. 8: 112-113

Manuscript first received: June 22, 1992

Revised version accepted: September 9, 1992 